\title{
ÍNDICES DE TRANSPARENCIA Y GESTIÓN EN LAS ENTIDADES PÚBLICAS COMO HERRAMIENTA DE CONTROL Y DESEMPEÑO: UNA COMPARACIÓN ENTRE INDICADORES MUNICIPALES EN ALAGOAS - BRASIL
}

\begin{abstract}
INDICES OF TRANSPARENCY AND MANAGEMENT IN PUBLIC ENTITIES AS A TOOL OF CONTROL AND PERFORMANCE: A COMPARISON BETWEEN MUNICIPAL INDICATORS EM ALAGOAS - BRAZIL
\end{abstract}

\author{
Juedir Viana Teixeira \\ Facultad de Ciencias Económicas \\ Universidad Nacional de Misiones \\ Posadas - Argentina \\ juedir@me.com
}

\author{
Artur Angelo Ramos Lamenha \\ Facultad de Ciencias Económicas \\ Universidad Nacional de Misiones \\ Posadas - Argentina \\ arturo.lamenha@gmail.com
}

Fecha de recepción: 03/10/2018 - Fecha de aprobación: 10/10/2018

\section{RESUMEN}

Esta investigación busca describir y correlacionar indicadores de gestión y control en gobiernos municipales. Para ello, se realizó una investigación descriptiva y cuantitativa, observando indicadores de eficiencia y transparencia de municipios en Alagoas que presentaban valores en instituciones de control y planificación a nivel nacional, correlacionando con otros indicadores de coyuntura de cada municipio. Para ello, se buscó referencias sobre transparencia y gobernanza pública, se recogió datos en sitios oficiales y se realizó el tratamiento estadístico para la identificación de las correlaciones entre los indicadores de la Escala Brasil Transparente, de Eficiencia en Gestión Municipal, del índice de Gestión Fiscal, del Producto Interno Bruto per cápita, del Fondo de Participación de los Municipios, del Traspaso a los municipios, de la Densidad Demográfica y del Grado de Urbanización de los municipios de Alagoas, pretendiendo hallar variables que puedan explicar las relaciones entre los indicadores. Finalmente, se concluye que existe una correlación entre los mismos, sobre todo entre los indicadores de transparencia y los municipios que reciben mayores aportes de recursos; se observa que los municipios no continúan con la transparencia necesaria para el conocimiento de la información por parte de la sociedad y, consecuentemente, inhibe la práctica de la gobernanza electrónica y de la participación del ciudadano en la gestión de las políticas públicas.

PALABRAS CLAVE: Gobernanza Electrónica; Indicadores de Transparencia; Control de Gestión.

"Visión de Futuro" Año 16, Volumen Nº 23 N¹, Enero - Junio 2019 - Pág. 75 - 96

URL de la Revista: http://revistacientifica.fce.unam.edu.ar/

URL del Documento: http://revistacientifica.fce.unam.edu.ar/index.php?option=com_content\&view=article\&id=492\&ltemid=101

ISSN 1668 - 8708 - Versión en Línea

E-mail: revistacientifica@fce.unam.edu.ar 
ABSTRACT

This research seeks to describe and correlate indicators of management and control in municipal governments. For this, a descriptive and quantitative research was carried out, observing indicators of efficiency and transparency of municipalities in Alagoas that presented values in institutions of control and planning at national level, correlating with other indicators of conjuncture of each municipality. For this purpose, references were sought on transparency and public governance, data was collected from official sites and the statistical treatment was performed to identify the correlations between the indicators of the Transparent Brazil Scale, Municipal Management Efficiency, the Fiscal Management Index, of the Gross Domestic Product per capita, of the Participation Fund of the Municipalities, of the Transfer to the municipalities, of the Demographic Density and of the Degree of Urbanization of the municipalities of Alagoas, trying to find variables that can explain the relations between the indicators. Finally, it is concluded that there is a correlation between them, especially between the transparency indicators and the municipalities that receive the greatest contributions of resources; it is observed that the municipalities do not continue with the necessary transparency for the knowledge of the information by society and, consequently, it inhibits the practice of electronic governance and the participation of the citizen in the management of public policies.

KEY WORDS: Electronic Governance; Indicators of Transparency; Management Control.

\section{INTRODUCCIÓN}

Según la Constitución Federal en Brasil, con refuerzo de la Ley de Acceso a la Información, la iniciativa de disponer información en Internet debe ser asumida con mucha responsabilidad por las entidades públicas, ya que se trata de un derecho fundamental del ciudadano, y que, al reducir su disponibilidad, tales instituciones públicas inhiben la participación del ciudadano en los procesos democráticos. Así, se presenta la necesidad de políticas generales de gobernanza electrónica, así como estrategias en el ámbito local para promover nuevos espacios de acceso e interacción popular; con el uso inteligente y político de Internet podrán hacer la diferencia a partir de cumplir ese rol de transformar la realidad actual, poco centrada en el ciudadano (Bernades et al, 2015).

La gobernanza pública, en sentido general, tiene como significado de cambio en el proceso de gobernar, y en la literatura sobre gobernanza, ese significado es capturado en la observación de los propios cambios y controversias sobre gobernanza y sus implicaciones, siendo la Gobernanza entendida también como estructura (la arquitectura de las instituciones formales e informales, definida

"Visión de Futuro" Año 16, Volumen N²3 N¹, Enero - Junio 2019 - Pág. 75 - 96

URL de la Revista: http://revistacientifica.fce.unam.edu.ar/

URL del Documento: http://revistacientifica.fce.unam.edu.ar/index.php?option=com_content\&view=article\&id=492\&ltemid=101

ISSN 1668 - 8708 - Versión en Línea

E-mail: revistacientifica@fce.unam.edu.ar 
algunas veces como sistemas de reglas, regímenes de leyes, reglas, decisiones judiciales y prácticas administrativas, redes o mercado), como proceso (la dinámica y la conducción de las funciones que involucran los procesos de formulación de políticas), como mecanismo (los procedimientos institucionales para la toma de decisiones, el control y la conformidad) y como estrategia (significa el diseño, la creación y la adaptación de los sistemas de gobernanza) (Levi-Faur, 2012).

Se considera importante la idea de gobernanza como un medio para conducir y obtener los recursos necesarios para la implementación y divulgación de las acciones colectivas en las sociedades contemporáneas. Así es principalmente el sector público que, a través de sus instituciones, forma las acciones colectivas. Sin embargo, la implementación de estas acciones implica la interacción de varios actores en los diversos niveles y esferas de gobierno y fuera de él también. El principal significado de la gobernanza es la capacidad de conducir (steer) u orientar la economía y la sociedad. Como la dirección es ofrecida por el Estado o por otras instituciones, o conjunto de instituciones, la lógica de la gobernanza es generar un conjunto coherente de objetivos, encontrar los medios y desarrollar los mecanismos para alcanzarlos, así como monitorear los efectos por ellos producidos. Este enfoque considera que una diversidad de actores está involucrada en los procesos decisorios y que existen objetivos conflictivos, que no siempre son conciliables. Así, algunos sistemas de gobernanza pueden involucrar objetivos a menudo incoherentes o incluso incompatibles (Peters, 2012).

Esta nueva configuración en la circulación de información repercute directamente en las relaciones sociales, principalmente en la utilización de mecanismos de gobernanza electrónica desde la perspectiva del ciudadano informado/informante, donde, de cierta manera, se abstrae la relación de autoridad, pasando a una relación de servicio de ciudadanía, con transparencia y la posibilidad de control, por parte de todos los que se encuentran insertos en el ámbito virtual (Lemos \& Levy, 2010).

Los portales electrónicos de los organismos públicos se utilizan para la prestación de servicios públicos a la sociedad de la manera más transparente posible, sobre todo por el volumen de recursos y por la gama de servicios extremadamente diversificados para un público diverso, con relación a clases económicas y culturales distintas. Las páginas en internet, o websites, poseen la capacidad de proporcionar acceso relativamente seguro, con rapidez y bajo costo, semejantes a las grandes corporaciones que adoptan estándares de gobernanza modernas.

A pesar de este nuevo paradigma electrónico de gestión pública en el contexto de la utilización de las modernas tecnologías de información y comunicación en la era del conocimiento, estudios señalan problemas coyunturales y/o estructurales en los portales electrónicos en los niveles regionales (Mello \& Slomski, 2010; Beuren, De Moura, \& Kloeppel, 2013; Sales, 2013; De Moura et al, 2013; De Souza, et al, 2013).

"Visión de Futuro" Año 16, Volumen N² 23 N¹, Enero - Junio 2019 - Pág. 75 - 96

URL de la Revista: http://revistacientifica.fce.unam.edu.ar/

URL del Documento: http://revistacientifica.fce.unam.edu.ar/index.php?option=com_content\&view=article\&id=492\&ltemid=101

ISSN 1668 - 8708 - Versión en Línea

E-mail: revistacientifica@fce.unam.edu.ar 
En este sentido, frente a estos aspectos, la problemática utilizada para guiar la construcción de esta investigación involucra la siguiente cuestión: ¿existe una relación entre los indicadores de transparencia y resultados con los indicadores económicos, financieros y sociales de la región? Frente a este problema, esta investigación posee como objetivo general comparar indicadores de transparencia y resultados mediante organismos oficiales, buscando relaciones entre los mismos, desde la perspectiva de dar continuidad a las discusiones sobre gobernanza electrónica a través de sus portales públicos, así como poner a disposición los resultados para la sociedad alagoana. Además, como objetivos específicos se busca la correlación de los resultados de los índices de la Escala Brasil Transparent - EBT, Índice de Eficiencia de la Gestión Municipales - IEGM, e Índice Firjan de la Gestión Fiscal - IFGF con otros de naturaleza socioeconómica de los municipios bajo estudio.

La relevancia de esta investigación se encuentra en la posibilidad de contribuir con la literatura académica, así como con el análisis y discusión de las políticas de Gobernanza Electrónica, entre usuarios, gestores públicos e investigadores sobre el tema, pudiendo contribuir con una mayor transparencia de la gestión y una mayor eficiencia en los servicios prestados a los ciudadanos.

El estudio se estructura en cinco secciones luego de esta introducción, donde son abordados: el tema, objetivos, problema y relevancia; la segunda sección trata el marco teórico, enfoques teóricos, gobernanza y gobierno electrónico y las posibilidades y limitaciones para la moderna gestión pública; la tercera sección aborda la metodología utilizada en la investigación; la cuarta proporciona un análisis de los datos; finalmente, se exponen las consideraciones finales.

\section{DESARROLLO}

\section{Principales abordajes teóricos}

Diversos trabajos sobre gobernanza electrónica a través de portales públicos en internet han sido realizados y presentados con el objetivo de medir el nivel de difusión o identificar los factores que determinan tales prácticas en lo que se refiere a la transparencia y eficiencia necesarias.

Para hacer una relación entre la reforma de la Administración Pública y las tecnologías de información, Dias (2011) cita la Teoría Institucional, incluyendo costos de transacción, fronteras de la firma, asimetría de la información y selección adversa.

En este mismo orden, Mello y Slomski (2010) destacan como principales tendencias teóricas sobre gobernanza electrónica: la Teoría de la Agencia, que trata de problemas resultantes de los conflictos de interés entre el agente - gestor público y el principal ciudadano, y cómo las partes efectúan sus contratos con transparencia y evidencia, con el propósito de minimizar los costos asociados a los problemas de información asimétrica e incertidumbre; la Teoría de la Elección Pública

"Visión de Futuro" Año 16, Volumen N²3 N¹, Enero - Junio 2019 - Pág. 75 - 96

URL de la Revista: http://revistacientifica.fce.unam.edu.ar/

URL del Documento: http://revistacientifica.fce.unam.edu.ar/index.php?option=com_content\&view=article\&id=492\&ltemid=101

ISSN 1668 - 8708 - Versión en Línea

E-mail: revistacientifica@fce.unam.edu.ar 
Índices de Transparencia y Gestión en las Entidades Públicas como Herramienta de Control y Desempeño: una comparación entre Indicadores Municipales en Alagoas - Brasil

- Public Choice - que describe cómo los gobiernos toman decisiones acerca de ingresos, gastos, reglamentaciones y otras políticas, con el fin de igualar la búsqueda de las personas por bienes colectivos con la capacidad económica para proporcionarlos; y la teoría de los costos de transacción, que trata del gasto de recursos necesarios para planear, adaptar y monitorear las interacciones entre los agentes, garantizando que el cumplimiento en términos contractuales se lleve a cabo de manera satisfactoria para las partes involucradas - gestores y ciudadanos - y compatible con su funcionalidad económica.

Desde la perspectiva de la utilización de las prácticas de gobierno electrónico para permitir la transparencia y accountability en las democracias, Freitas (2011) enfatiza la Teoría de la Agencia y establece como principales elementos en el proceso de información para el ejercicio de la ciudadanía el control (accountability), el principal (ciudadano) y los agentes (representantes del poder público).

El estudio de Beuren (2013) establece una relación entre la Teoría de la Legitimidad y el costo público de las entidades que publican información obligatoria y voluntaria para satisfacer las demandas de la legislación, pues las mismas deben demostrar constantemente a la sociedad su importancia y legitimar sus actos y evidenciar el cumplimiento del contrato social existente entre la sociedad y la empresa. Los autores infieren que el Estado considera el costo político del aumento de los niveles y calidad de la divulgación frente a la pérdida de la legitimidad, ya que las organizaciones poseen costos políticos potencialmente elevados cuando se sienten amenazadas en su legitimidad, deben ampliar la divulgación obligatoria y voluntaria, recuperando o disminuyendo la posibilidad de pérdida de la legitimidad.

Algunos estudios sobre la divulgación de información financiera a través de internet, conocidos como Internet Financial Reporting - IFR, también generan contribuciones teóricas importantes para el análisis de las prácticas digitales en portales públicos, tales como la teoría de la agencia, la teoría de la legitimidad, la teoría de la señalización, la teoría de los stakeholders, la teoría institucional y la teoría de la difusión de la innovación (An et al, 2011; Magalhães et al, 2012).

El estudio de Magalhães et. al, (2012), analizó algunas prácticas sobre Internet Financial Reporting - IFR, principalmente el marco teórico presentado por An et al. (2011), con el objetivo de proporcionar otras perspectivas teóricas relacionadas con las prácticas de IFR. De acuerdo con el estudio citado, las principales teorías son: 1) Teoría de la agencia - En el caso del sector público, el ciudadano es el principal y el gestor público es el agente, y una forma de reducir los costos de agencia es aumentar la cantidad de información para la sociedad, de acuerdo con los estudios de An et. al (2011) y Cerrillo-i-Martínez (2011); 2) Teoría de la legitimidad - La divulgación voluntaria de información financiera a través de internet puede ser considerada como una fuerte señal de legitimidad de las organizaciones públicas frente a la sociedad, según An et. al (2011); 3) Teoría de la señalización -

"Visión de Futuro" Año 16, Volumen Nº 23 N¹, Enero - Junio 2019 - Pág. 75 - 96

URL de la Revista: http://revistacientifica.fce.unam.edu.ar/

URL del Documento: http://revistacientifica.fce.unam.edu.ar/index.php?option=com_content\&view=article\&id=492\&ltemid=101

ISSN 1668 - 8708 - Versión en Línea

E-mail: revistacientifica@fce.unam.edu.ar 
Existe una tendencia de que la gestión pública posea más información sobre las operaciones de la organización pública que los ciudadanos, sugiriendo que la divulgación voluntaria de información en websites surge como una forma de señalizar una alta calidad de la gestión de la organización, con prácticas modernas y actualizadas con tecnologías, de acuerdo con los trabajos de Aly et al., (2010) e An et al., (2011); 4) Teoría de los stakeholders - La difusión electrónica voluntaria podría disminuir la asimetría de la información entre la organización y los stakeholders y, como consecuencia, mejorar las relaciones entre ellos, de acuerdo con los estudios de An et al., (2011); 5) Teoría del cambio institucional - Una organización pública puede adoptar internet como un medio de difusión financiera por imposición legal (isomorfismo coercitivo), para parecerse a las demás organizaciones públicas del mismo sector (isomorfismo mimético), o inclusive, como consecuencia de la influencia que establecen los órganos relacionados con la profesión contable (Magalhães et al, 2012); 6) Teoría de la difusión de la innovación - Las prácticas de difusión electrónica de información por parte de las organizaciones públicas dependerán de cómo estas perciban sus ventajas relativas y su compatibilidad (Magalhães et al, 2012).

A través de las teorías presentadas en esta sección, se percibe que, a pesar de la proximidad entre las mismas, todas se complementan para explicar las prácticas de difusión de la información a través de internet y que, principalmente, las teorías de la agencia, stakeholders e institucional son fundamentales para contribuir con la explicación del fenómeno sobre la utilización de los portales públicos para la divulgación de información en internet.

Diversas investigaciones sobre las prácticas de gobernanza electrónica a través de portales públicos de estados y municipios fueron realizadas y presentadas en trabajos científicos en varias regiones de Brasil. Los trabajos tuvieron como foco principal los elementos que influyeron sobre las prácticas de gobernanza electrónica a través de portales públicos, así como sugerencias de indicadores que pudiesen identificar las variables propuestas por Mello y Slomski (2010) en lo referente a la prestación de servicios públicos y la participación ciudadana. Algunos estudios (Cordeiro et al., 2012; Raupp y Pinho, 2012) incluyeron las redes sociales virtuales en el escenario, con base en las perspectivas de que se destacará la importancia de estas herramientas en la disposición de los servicios de información que contribuyen significativamente en la prestación de los servicios y la democratización de la gestión pública.

El trabajo de Mello y Slomski (2010) identificó un conjunto de prácticas de gobernanza electrónica para los estados brasileños y el Distrito Federal y realizó una relación con sus respectivos desarrollos económico y social, además de contribuir con la construcción de un marco teórico sobre la gobernanza electrónica y de formar un Índice de Gobernanza Electrónica de los Estados Brasileños - IGEB. Los resultados de la investigación demostraron que los estados de São Paulo, Rio Grande do Sul, Rio de

\footnotetext{
"Visión de Futuro" Año 16, Volumen N²3 N¹, Enero - Junio 2019 - Pág. 75 - 96

URL de la Revista: http://revistacientifica.fce.unam.edu.ar/

URL del Documento: http://revistacientifica.fce.unam.edu.ar/index.php?option=com_content\&view=article\&id=492\&ltemid=101

ISSN 1668 - 8708 - Versión en Línea

E-mail: $\underline{\text { revistacientifica@fce.unam.edu.ar }}$
} 
Índices de Transparencia y Gestión en las Entidades Públicas como Herramienta de Control y Desempeño: una comparación entre Indicadores Municipales en Alagoas - Brasil

Janeiro, Espírito Santo, Paraná, Bahía y Minas Gerais fueron los que contaban con más prácticas implementadas y concluyó que los mismos eran más desarrollados, o sea, con mayor Producto Interno Bruto - PBI, mayor Índice de Desarrollo Humano - IDH y menor Gini.

Raupp y Pinho (2010) investigaron las condiciones de construcción de la accountability en portales electrónicos de cámaras municipales con más de 50.000 habitantes, a partir de indicadores de rendición de cuentas, de transparencia y de participación / interacción, concluyendo que los portales del legislativo poseen una baja capacidad de construcción de la accountability, pues la mayoría de estos indicadores se encuentran clasificados en estratos de baja y media capacidad, así como por los estados contables que son divulgados parcialmente y a veces, fuera de tiempo. Además, investigando portales electrónicos del poder legislativo, otro estudio de Raupp y Pinho (2013) comparó la rendición de cuentas de 52 portales de Cámaras Municipales de los estados de Bahía y de Santa Catarina, y concluye que la única motivación para que los concejales rindan cuentas es la existencia de una legislación que los obliga y, asimismo, pocas cámaras lo hacen, mostrando negligencia de los parlamentarios respecto a la difusión de información relacionada con los gastos incurridos en el Legislativo.

En esta línea, Moura et al., (2011) analizaron las prácticas de gobernanza electrónica de municipios del estado de Santa Catarina, descartando aquellos con poblaciones superiores a los 20 mil habitantes y verificaron su correlación con las variables del PBI, IDH y tamaño. Los autores concluyeron que los municipios mayores y con mejores condiciones socioeconómicas, representadas por el IDH y el PBI, arrojaron un mayor número de prácticas de gobernanza electrónica.

Beuren et al., (2013) analizaron las prácticas de gobernanza electrónica de los 26 estados brasileños y realizaron una correlación con la eficiencia en la utilización de los ingresos, evidenciando que los estados con mayores prácticas se localizan en la región sudeste, y que los mismos poseen una mayor eficiencia en la utilización de los ingresos.

Souza (2014) realizó un estudio en los portales de los municipios más populosos de Brasil, concluyendo que estos presentan elementos que caracterizan al gobierno electrónico, pero enfatiza la distancia de un modelo de gobernanza electrónica y sus beneficios, mucho debido a la falta de incentivo y participación popular en las decisiones del gobierno, que corresponde a la pieza fundamental de una buena gobernanza electrónica.

La investigación de Freitas y Luft (2014) verificó los índices de gobernanza electrónica en los municipios del Estado de Sergipe, a través de sus websites. Los resultados señalaron índices de gobernanza electrónica bajos y que los sitios municipales de pequeño porte y con poca capacidad tenían apenas un carácter informativo, resaltando su etapa de construcción de una cultura de utilización de las TIC.

"Visión de Futuro" Año 16, Volumen Nº 23 N¹, Enero - Junio 2019 - Pág. 75 - 96

URL de la Revista: http://revistacientifica.fce.unam.edu.ar/

URL del Documento: http://revistacientifica.fce.unam.edu.ar/index.php?option=com_content\&view=article\&id=492\&ltemid=101

ISSN 1668 - 8708 - Versión en Línea

E-mail: revistacientifica@fce.unam.edu.ar 
El artículo de Moura et al (2013) tenía como objetivo analizar las prácticas de gobernanza electrónica en 99 municipios de la región sur de Brasil, bajo la óptica de la teoría de la legitimidad, de acuerdo con las practicas sugeridas por Mello y Slomski (2010). Se concluye, de manera general, que muchos municipios no poseían un gran número de prácticas de gobernanza electrónica analizadas, perjudicando de cierta forma el acceso a la información y al conocimiento sobre el proceso político.

Matos (2013) pretendió evaluar el nivel de transparencia de la información divulgada en los portales de transparencia de los 30 municipios más poblados de la región nordeste y verificó que los gestores municipales que disponen de más información sobre su gestión también han demostrado una postura de mayor disposición con la práctica de la accountability, con una mayor repetición en los municipios con mejores indicadores socioeconómicas, pero, sin embargo, se encuentran en desacuerdo con las exigencias legales en relación a la transparencia y a la información disponible.

La gobernanza electrónica puede ser conceptualizada como el uso de las modernas tecnologías de información y comunicación, principalmente internet, por parte de organismos públicos, con el propósito de promover un acceso rápido, transparente y eficiente de difusión de la información de interés de los ciudadanos, para incentivar la participación efectiva de estos y para la realización de actividades administrativas del gobierno (Mello y Slomski, 2010).

A pesar de estas posibilidades de beneficios, los autores también destacan la necesidad de considerar un Estado más sensible, abierto a la participación de la sociedad de manera transparente y democrática, y por otro lado, la sociedad civil, atribuyéndosele un papel propositivo por intermedio de los ciudadanos y/o de movimientos sociales, para evaluar y controlar al gobierno, lo que demanda no solo un rol democrático del mismo, sino también una capacidad política de la sociedad civil.

En este sentido, los portales públicos en internet surgen como elementos que facilitan la participación de la sociedad en el gobierno y en el ejercicio del control social. Se verifica la existencia de mucha tecnología en las prácticas de la gobernanza electrónica, pero aún con la necesidad de expansión hacia toda la sociedad, pues se identifica poca democracia en el proceso por cuestiones de cultura política, indicando falta de transparencia y en la impermeabilidad de la sociedad civil.

Se entiende, en este estudio, que la gobernanza electrónica es una tendencia y un elemento fundamental para el gestor público, ya sea mediante la legislación sobre la transparencia y eficiencia necesarias o por la exigencia de los ciudadanos y de la sociedad organizada. Sales (2013) destaca la posibilidad de participación en la vida política de grupos socialmente excluidos, debido a la facilidad de acceso mediante internet con la administración pública, promoviendo cambios en la cultura política de desinterés por parte de diversos sectores de la gestión pública, siendo un problema de la cultura y desarrollo político y no de la tecnología propiamente dicha.

\footnotetext{
“Visión de Futuro" Año 16, Volumen Nº 23 N¹, Enero - Junio 2019 - Pág. 75 - 96

URL de la Revista: http://revistacientifica.fce.unam.edu.ar/

URL del Documento: http://revistacientifica.fce.unam.edu.ar/index.php?option=com content\&view=article\&id=492\&ltemid=101

ISSN 1668 - 8708 - Versión en Línea

E-mail: $\underline{\text { revistacientifica@fce.unam.edu.ar }}$
} 
Índices de Transparencia y Gestión en las Entidades Públicas como Herramienta de Control y Desempeño: una comparación entre Indicadores Municipales en Alagoas - Brasil

Frente a lo expuesto, se verifica la importancia de observar la relación entre los indicadores de transparencia, económicos, contables y sociales, de distintas instituciones de control, y cómo estos se relacionan entre sí. Para ello, con base en el marco referencial presentado, se buscaron los principales indicadores de los órganos de control y, a continuación, se presenta la metodología y el análisis de los datos.

\section{Metodología}

Esta investigación puede ser clasificada como descriptiva y cuantitativa, observando indicadores de eficiencia, transparencia y resultados de los municipios en Alagoas, correlacionando con indicadores económicos y financieros de cada municipio, en 2017, con el objetivo de establecer si existe relación entre los mismos. Para ello, se buscó referenciales sobre eficiencia, transparencia y gobernanza pública, pretendiendo resultados. A continuación, se llevó a cabo el tratamiento estadístico para la identificación de las correlaciones positivas entre los indicadores de la Escala Brasil Transparente - EBT, de Eficiencia en Gestión Municipal - IEGM, Índice FIRHAN de Gestión Fiscal IFGF, PBI per cápita, Fondo de Participación de los Municipios - FPM, traspaso a los municipios alagoanos, densidad demográfica y grado de urbanización en los municipios de Alagoas en el PBI.

De acuerdo con Gil (2017), el coeficiente de correlación puede ser considerado: positivo perfecto $(=1,0)$; positivo muy fuerte (de 0,70 a 0,99 ); positivo substancial (de 0,50 a 0,69 ); positivo moderado (de 0,30 a 0,49); positivo bajo (de 0,10 a 0,29); positivo ínfimo (0,01 a 0,09); sin correlación (0,00); negativo ínfimo (de - 0,01 a 0,09); negativo bajo (de - 0,10 a 0,29); negativo moderado (de - 0,30 a 0,49 ); negativo substancial (de - 0,50 a 0,69 ); negativo muy fuerte (de - 0,70 a 0,99 ) y; negativo perfecto $(=-1,0)$.

El relevamiento observó indicadores de los 102 municipios de Alagoas, buscando información sobre los principales indicadores de eficiencia, transparencia y resultados de la gestión de los municipios que corresponden al ejercicio 2017, de acuerdo con las medidas metodológicas de los institutos responsables, tales como: Ministerio de la Transparencia y Auditoria General de la Unión CGU, Instituto Rui Barbosa - IRB, una organización civil, sin fines lucrativos, fundada en 1973 por los Tribunales de Cuentas de Brasil, con la función de mejorar las actividades ejercidas por los Tribunales de Cuentas, a través de la promoción de estudios, investigaciones, capacitaciones, seminarios y congresos; Sistema Firjan, que es una red de organizaciones privadas sin fines de lucro con más de diez mil asociados, con la misión de promover la competitividad empresarial, la educación y la calidad de vida de los trabajadores industriales y de toda la sociedad; Instituto Brasileño de Geografía y Estadística - IBGE y la Secretaría de Planeamiento del Estado de Alagoas. Luego del relevamiento

"Visión de Futuro" Año 16, Volumen N² 23 N¹, Enero - Junio 2019 - Pág. 75 - 96

URL de la Revista: http://revistacientifica.fce.unam.edu.ar/

URL del Documento: http://revistacientifica.fce.unam.edu.ar/index.php?option=com_content\&view=article\&id=492\&ltemid=101

ISSN 1668 - 8708 - Versión en Línea

E-mail: revistacientifica@fce.unam.edu.ar 
bibliográfico y documental y del análisis de los indicadores, fueron tabulados los resultados, analizados y correlacionados entre sí mediante el software EXCEL 2016 con suplemento XLSAT.

\section{Principales Indicadores Institucionales de Transparencia, Gestión y Eficiencia}

La Escala Brasil Transparente - EBT es una medida de transparencia utilizada por el Ministerio de la Transparencia y Auditoría General de la Unión, que aplica una metodología mediante un listado compuesto por 12 requisitos que alcanzan aspectos de la regulación del acceso a la información y la existencia y funcionamiento del Servicio de Información al Ciudadano - SIC, realizándose cuatro pedidos de acceso a la información, siendo tres centrados en temas de las principales áreas sociales: salud, educación y asistencia social; la cuarta solicitud de información se refiere a la reglamentación del acceso por parte del ente evaluado, sirviendo inclusive como una pregunta de seguridad para la medición realizada sobre la existencia de la normativa local, evaluándose los siguientes puntos: I Reglamentación de la Ley de Acceso (Exposición de la legislación en el sitio del evaluado; Existencia de reglamentación; Reglamentación del SIC; Reglamentación de la clasificación del sigilo; Reglamentación de la responsabilidad del servidor; Reglamentación de instancias recusarles) y II Transparencia pasiva (Difusión del SIC físico con atención personal; Existencia de un e-SIC con atención por internet; Posibilidad de seguimiento del pedido de acceso; Inexistencia de puntos que dificulten o no permitan el pedido de acceso; Respuestas a los pedidos dentro del plazo legal; Respuestas en conformidad con lo que fue solicitado).

De acuerdo con su anuario (2015), el IEGM Brasil es el índice de desempeño elaborado por el IRB y difundido a los demás Tribunales de Cuentas de Brasil, compuesto por 7 índices sectoriales, los cuales son: Educación (evaluación escolar, planificación de cupos, actuación del Consejo Municipal de Educación, problemas de infraestructura, merienda escolar, situación y calificación de los profesores, cantidad de vacantes, material y uniforme escolar); Salud (cobertura y acción de los Programas de Salud de la Familia, actuación del Consejo Municipal de Salud, asiduidad de los médicos, atención a la población para tratamiento de enfermedades como la tuberculosis y prevención de enfermedades como el dengue, control de stock de insumos, cobertura de las campañas de vacunación y de orientación a la población); Planificación (cumplimiento de lo que fue planificado, coherencia entre las metas físicas alcanzadas, los recursos empleados, los resultados logrados por las acciones y sus reflejos en los indicadores del programa); Gestión Fiscal (análisis de la ejecución financiera y presupuestaria de las decisiones en relación a la aplicación de recursos vinculados, de la transparencia de la administración municipal y de la obediencia a los límites establecidos por la Ley de Responsabilidad Fiscal); Medio Ambiente (sobre residuos sólidos, saneamiento básico, educación ambiental, estructura ambiental y consejo ambiental); Ciudades Protegidas (Plan de contingencia,

\footnotetext{
"Visión de Futuro" Año 16, Volumen N²3 N¹, Enero - Junio 2019 - Pág. 75 - 96

URL de la Revista: http://revistacientifica.fce.unam.edu.ar/

URL del Documento: http://revistacientifica.fce.unam.edu.ar/index.php?option=com_content\&view=article\&id=492\&ltemid=101

ISSN 1668 - 8708 - Versión en Línea

E-mail: revistacientifica@fce.unam.edu.ar
} 
identificación de riesgos para la intervención del Poder Público, infraestructura de la Defensa Civil); Gobernanza en Tecnología de la Información (políticas de uso de la informática, seguridad de la información, capacitación del personal y transparencia); generando los siguientes índices componentes del IEGM Brasil:

-El índice FIRJAN de Gestión Fiscal - IFGF, es un índice elaborado en base a diversas estadísticas oficiales, a partir de datos declarados por los municipios a la Secretaría del Tesoro Nacional - SNT, buscándose mediante este índice contribuir con la eficiencia y participación ciudadana en las políticas públicas. En esta línea, el índice es considerado una herramienta de control social que tiene como fin estimular la responsabilidad administrativa, mejorar la gestión fiscal de los municipios y perfeccionar las decisiones de los gestores públicos en la distribución de recursos, pretendiéndose, mediante su metodología, comparar e interpretar los datos relevados por los estados y por cada uno de los municipios, adoptándose la siguiente clasificación: Gestión de la Excelencia, Buena Gestión, Gestión en Dificultades y Gestión Critica. 
Tabla №1. Indicadores de transparencia, gestión, eficiencia y variables de los municipios de Alagoas

\begin{tabular}{|c|c|c|c|c|c|c|c|c|c|}
\hline ORD & CÓDIGO & MUNICÍPIO & EBT/CGU & IFGF & IEGM & FPM & $\begin{array}{c}\text { GRAU DE } \\
\text { URBANIZAÇÃO }\end{array}$ & $\begin{array}{l}\text { PIB PER } \\
\text { CAPITA }\end{array}$ & $\begin{array}{c}\text { DENSIDADE } \\
\text { DEMOGRÁFICA }\end{array}$ \\
\hline 1 & 270430 & Maceió & 10,000 & 0,529 & 0,500 & 22,244 & $\begin{array}{r}99,934 \\
\end{array}$ & $13.263,666$ & $1.854,115$ \\
\hline 2 & 270550 & Murici & 6,660 & 0,689 & 0,750 & 0,897 & 82,770 & $5.282,721$ & 62,580 \\
\hline 3 & 270520 & Messias & 6,110 & 0,564 & 0,550 & 0,769 & 90,951 & $5.535,084$ & 137,773 \\
\hline 4 & 270880 & São Sebastião & 5,690 & 0,434 & 0,500 & 1,026 & 38,454 & $5.624,485$ & 101,586 \\
\hline 5 & 270840 & São José da Tapera & 5,270 & 0,560 & 0,600 & 1,026 & 38,677 & $3.514,305$ & 60,770 \\
\hline 6 & 270030 & Arapiraca & 4,860 & 0,521 & 0,575 & 4,546 & 84,802 & $8.917,205$ & 600,838 \\
\hline 7 & 270900 & Tanque d'Arca & 3,880 & 0,296 & 0,275 & 0,385 & 34,956 & $3.843,423$ & 47,271 \\
\hline 8 & 270830 & São José da Laje & 3,610 & 0,458 & 0,400 & 0,897 & 67,844 & $8.805,626$ & 88,396 \\
\hline 9 & 270440 & Major Isidoro & 3,330 & 0,294 & 0,400 & 0,769 & 49,246 & $4.602,249$ & 41,633 \\
\hline 10 & 270630 & Palmeira dos Índios & 3,330 & 0,367 & 0,375 & 1,667 & 73,343 & $6.305,934$ & 155,440 \\
\hline 11 & 270470 & Marechal Deodoro & 2,770 & 0,600 & 0,275 & 1,410 & 94,378 & $4.693,706$ & 138,619 \\
\hline 12 & 270110 & Branquinha & 2,500 & 0,548 & 0,300 & 0,513 & 63,054 & $6.158,873$ & 63,630 \\
\hline 13 & 270750 & Porto Real do Colégio & 2,500 & 0,347 & 0,300 & 0,769 & 34,168 & $4.784,306$ & 79,913 \\
\hline 14 & 270910 & Taquarana & 2,220 & 0,493 & 0,600 & 0,769 & 38,454 & $4.937,882$ & 114,547 \\
\hline 15 & 270060 & Barra de São Miguel & 1,940 & 0,444 & 0,400 & 0,385 & 86,097 & $8.954,022$ & 98,858 \\
\hline 16 & 270270 & Feliz Deserto & 1,940 & 0,300 & 0,475 & 0,385 & 80,115 & $15.665,291$ & 47,311 \\
\hline 17 & 270420 & Limoeiro de Anadia & 1,940 & 0,345 & 0,325 & 0,897 & 8,321 & $3.624,169$ & 85,478 \\
\hline 18 & 270600 & Olivença & 1,940 & 0,333 & 0,425 & 0,513 & 28,397 & $3.811,647$ & 63,870 \\
\hline 19 & 270810 & Santana do Mundaú & 1,940 & 0,625 & 0,250 & 0,513 & 51,619 & $18.130,665$ & 48,757 \\
\hline 20 & 270920 & Traipu & 1,940 & 0,790 & 0,600 & 0,897 & 31,231 & $3.278,864$ & 36,824 \\
\hline 21 & 270930 & União dos Palmares & 1,660 & 0,350 & 0,475 & 1,539 & 76,415 & $7.010,424$ & 148,239 \\
\hline 22 & 270390 & Jundiá & 1,380 & 0,467 & 0,475 & 0,385 & 67,277 & $6.837,568$ & 45,563 \\
\hline 23 & 270510 & Matriz de Camaragibe & 1,380 & 0,343 & 0,350 & 0,897 & 92,899 & $5.427,132$ & 108,119 \\
\hline 24 & 270890 & Satuba & 1,380 & 0,235 & 0,225 & 0,513 & 87,598 & $5.334,872$ & 342,568 \\
\hline 25 & 270120 & Cacimbinhas & 1,110 & 0,324 & 0,300 & 0,513 & 52,987 & $4.112,696$ & 37,347 \\
\hline
\end{tabular}

Fuente: Elaboración Propia

A partir del relevamiento de los datos sobre los indicadores de la Escala Brasil Transparente de los municipios - EBT/CGU, IEGM/IRB, y Índice Firjan de Gestión Fiscal - IFGF/FIRJAN, además de las consultas sobre datos de los municipios alagoanos en el portal de transparencia de la Secretaría de Planeamiento y Gestión - SEPLAG, estos fueron cruzados, arreglados, tabulados y presentados de acuerdo con la Tabla No1.

Con el objetivo de correlacionar las variables entre sí, solamente se utilizaron los indicadores de 25 municipios de Alagoas que presentaban información sobre todas las variables. Dada la ausencia de información, nótese un bajo grado de representación de datos de transparencia si consideramos los indicadores EBT, IFGF e IEGM, de acuerdo con el cartograma.

\footnotetext{
"Visión de Futuro" Año 16, Volumen No 23 N¹, Enero - Junio 2019 - Pág. 75 - 96

URL de la Revista: http://revistacientifica.fce.unam.edu.ar/

URL del Documento: http://revistacientifica.fce.unam.edu.ar/index.php?option=com_content\&view=article\&id=492\&ltemid=101

ISSN 1668 - 8708 - Versión en Línea

E-mail: revistacientifica@fce.unam.edu.ar
} 


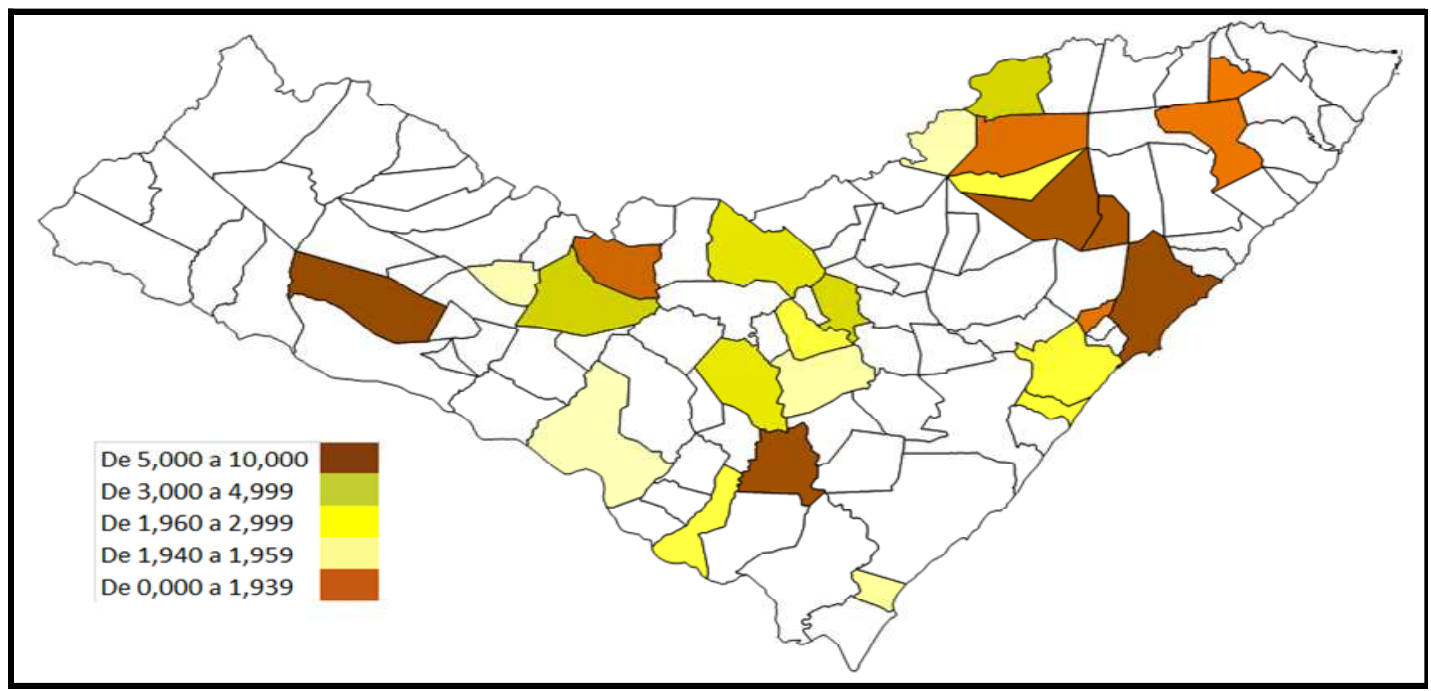

Figura №1. Indicadores de la EBT, IFGF e IEGM con información relativa a Alagoas Fuente: Elaboración Propia

\section{Análisis EBT/CGU y FPM, Grado de Urbanización, PIB per cápita y Densidad Demográfica}

A continuación, luego de la tabulación, arreglo y presentación de los índices, fueron realizadas las correlaciones entre el indicador EBT/CGU y los indicadores FPM, Grado de Urbanización, PBI per cápita y Densidad Demográfica para verificar las siguientes hipótesis:

$\mathrm{H}_{1}=$ Existe una correlación entre el indicador EBT y el FPM en municipios de Alagoas;

$\mathrm{H}_{2}=$ Existe una correlación entre el indicador EBT y el Grado de Urbanización en municipios de Alagoas;

$\mathrm{H}_{3}=$ Existe una correlación entre el indicador EBT y el PIB per cápita en municipios de Alagoas;

$\mathrm{H}_{4}=$ Existe una correlación entre el indicador EBT y la Densidad Demográfica en municipios de Alagoas.

Luego de efectuada la correlación entre el índice EBT/CGU y las variables: FPM, Grado de Urbanización, PBI per cápita y Densidad Demográfica, se presenta un F de significación de 0,004602, muy bajo de 0,05 y el Valor-p de 0,0011902 en la intersección, demostrando que la correlación entre las variables es significativa, así como el R-Cuadrado (coeficiente de determinación) que posee un $51,29 \%$ de impacto sobre el indicador de transparencia. El coeficiente Alfa de Cronbach fue de 0,81, bastante significativo también. Entonces, de acuerdo con lo expuesto, se pueden responder y confirmar las hipótesis, conforme a la matriz presentada a continuación:

\footnotetext{
"Visión de Futuro" Año 16, Volumen Nº 23 N¹, Enero - Junio 2019 - Pág. 75 - 96

URL de la Revista: http://revistacientifica.fce.unam.edu.ar/

URL del Documento: http://revistacientifica.fce.unam.edu.ar/index.php?option=com_content\&view=article\&id=492\&ltemid=101

ISSN 1668 - 8708 - Versión en Línea

E-mail: revistacientifica@fce.unam.edu.ar
} 
Tabla №2. Matriz de correlación entre los indicadores

\begin{tabular}{lccccc}
\hline & EBT/CGU & FPM & $\begin{array}{c}\text { GRADO DE } \\
\text { URBANIZACIÓN }\end{array}$ & $\begin{array}{c}\text { PBI PER } \\
\text { CAPITA }\end{array}$ & $\begin{array}{c}\text { DENSIDAD } \\
\text { DEMOGRÁFICA }\end{array}$ \\
\hline EBT/CGU & $\mathbf{1}$ & 0,695 & 0,268 & 0,136 & 0,665 \\
FPM & 0,695 & $\mathbf{1}$ & 0,347 & 0,355 & $\mathbf{0 , 9 8}$ \\
GRADO DE URBANIZACIÓN & 0,268 & 0,347 & $\mathbf{1}$ & 0,385 & 0,416 \\
PBI PER CAPITA & 0,136 & 0,355 & 0,385 & $\mathbf{1}$ & 357 \\
DENSIDAD DEMOGRÁFICA & 0,665 & $\mathbf{0 , 9 8}$ & 0,416 & 0,357 & $\mathbf{1}$ \\
\hline
\end{tabular}

Fuente: Elaboración Propia

Con esto, se comprueban las siguientes hipótesis presentadas:

$\mathrm{H}_{1}=$ Existe una correlación positiva y substancial de 0,695 entre el indicador EBT y el FPM en municipios de Alagoas;

$\mathrm{H}_{2}=$ Existe una correlación positiva baja de 0,268 entre el indicador EBT y el Grado de Urbanización en municipios de Alagoas;

$\mathrm{H}_{3}=$ Existe una correlación positiva baja de 0,136 entre el indicador EBT y el PIB per cápita en municipios de Alagoas;

$\mathrm{H}_{4}=$ Existe una correlación positiva substancial de 0,665 entre el indicador EBT y la Densidad Demográfica en municipios de Alagoas.

\section{Análisis EBT/CGU, IFGF e IEGM}

Luego del análisis presentado, fueron realizadas nuevas tabulaciones, arreglos y correlaciones entre el indicador EBT/CGU y los indicadores IFGF y IEGM para verificar las siguientes hipótesis:

$\mathrm{H}_{5}=$ Existe una correlación entre el indicador EBT y el IFGF en municipios de Alagoas;

$\mathrm{H}_{6}=$ Existe una correlación entre el indicador EBT y el IEGM en municipios de Alagoas;

A continuación, se realizó una estadística descriptiva considerando las relaciones entre los indicadores, que permitieron extrapolar las distribuciones normales de cada uno de ellos, así como verificar la confiabilidad mediante un Alfa de Cronbach de 0,719, un F de significación de 0,036235, debajo de 0,05 , demostrando una posible correlación significativa, pero con un R-Cuadrado (coeficiente de determinación) de solamente 26,03\%.

\footnotetext{
"Visión de Futuro" Año 16, Volumen N²3 N¹, Enero - Junio 2019 - Pág. 75 - 96

URL de la Revista: http://revistacientifica.fce.unam.edu.ar/

URL del Documento: http://revistacientifica.fce.unam.edu.ar/index.php?option=com_content\&view=article\&id=492\&ltemid=101

ISSN 1668 - 8708 - Versión en Línea

E-mail: revistacientifica@fce.unam.edu.ar
} 
Índices de Transparencia y Gestión en las Entidades Públicas como Herramienta de Control y Desempeño: una comparación entre Indicadores Municipales en Alagoas - Brasil

Tabla N3. Estadísticas descriptivas - Datos cuanti tativos

\begin{tabular}{|c|l|l|l|}
\hline Estadística & EBT/CGU & IFGF & IEGM \\
\hline $\mathrm{N}^{\circ}$ de observaciones & 25 & 25 & 25 \\
\hline Mínimo & 1,110 & 0,235 & 0,225 \\
\hline Máximo & 10,000 & 0,790 & 0,750 \\
\hline $1^{\circ}$ Cuartil & 1,940 & 0,343 & 0,300 \\
\hline Mediana & 2,500 & 0,444 & 0,400 \\
\hline $3^{\circ}$ Cuartil & 3,880 & 0,548 & 0,500 \\
\hline Media & 3,252 & 0,450 & 0,428 \\
\hline Varianza (n-1) & 4,533 & 0,020 & 0,018 \\
\hline Desvio-estándar (n-1) & 2,129 & 0,140 & 0,135 \\
\hline
\end{tabular}

Fuente: Elaboración Propia

Luego del análisis descriptivo se realizaron otras pruebas estadísticas para calcular la correlación entre los indicadores y se encontraron los siguientes resultados:

Tabla N4. Test de esfericidad de Bartlett

\begin{tabular}{|c|c|}
\hline Chi cuadrado (Valor observado) & 13,815 \\
\hline Chi cuadrado (Valor crítico) & 7,815 \\
\hline GL & 3 \\
\hline p-valor & 0,003 \\
\hline alfa & 0,05 \\
\hline
\end{tabular}

Fuente: Elaboración Propia

Interpretación del test:

HO: No hay correlaciones significativamente diferentes de 0 entre las variables.

Ha: Al menos una de las correlaciones entre las variables es significativamente diferente de 0 .

Como el $p$-valor calculado es menor que el nivel de significancia alfa $=0,05$, se debe rechazar la hipótesis nula $\mathrm{HO}$ a favor de la hipótesis alternativa $\mathrm{Ha}$.

El riesgo de rechazar la hipótesis nula $\mathrm{H} 0$ cuando esta es verdadera es menor a $0,32 \%$.

Tabla №5. Matriz de proximidad (Coeficiente de correlación de Pearson)

\begin{tabular}{|l|c|c|c}
\hline & EBT/CGU & IFGF & IEGM \\
\hline EBT/CGU & $\mathbf{1}$ & 0,359 & 0,497 \\
\hline IFGF & 0,359 & $\mathbf{1}$ & 0,524 \\
\hline IEGM & 0,497 & 0,524 & $\mathbf{1}$ \\
\hline
\end{tabular}

Fuente: Elaboración Propia

Los datos de las estadísticas descriptivas son los que se presentan a continuación y muestran el ploteo (Box Plot) y la posición de los datos de acuerdo con el análisis de los 3 indicadores y la posición

\footnotetext{
"Visión de Futuro" Año 16, Volumen N² 23 N¹, Enero - Junio 2019 - Pág. 75 - 96

URL de la Revista: http://revistacientifica.fce.unam.edu.ar/

URL del Documento: http://revistacientifica.fce.unam.edu.ar/index.php?option=com_content\&view=article\&id=492\&ltemid=101

ISSN 1668 - 8708 - Versión en Línea

E-mail: revistacientifica@fce.unam.edu.ar
} 
de los datos demostrando una distribución simétrica en los indicadores IFGF e IEGM, pues poseen la mediana en el centro del rectángulo, siendo considerados positivamente asimétricos:
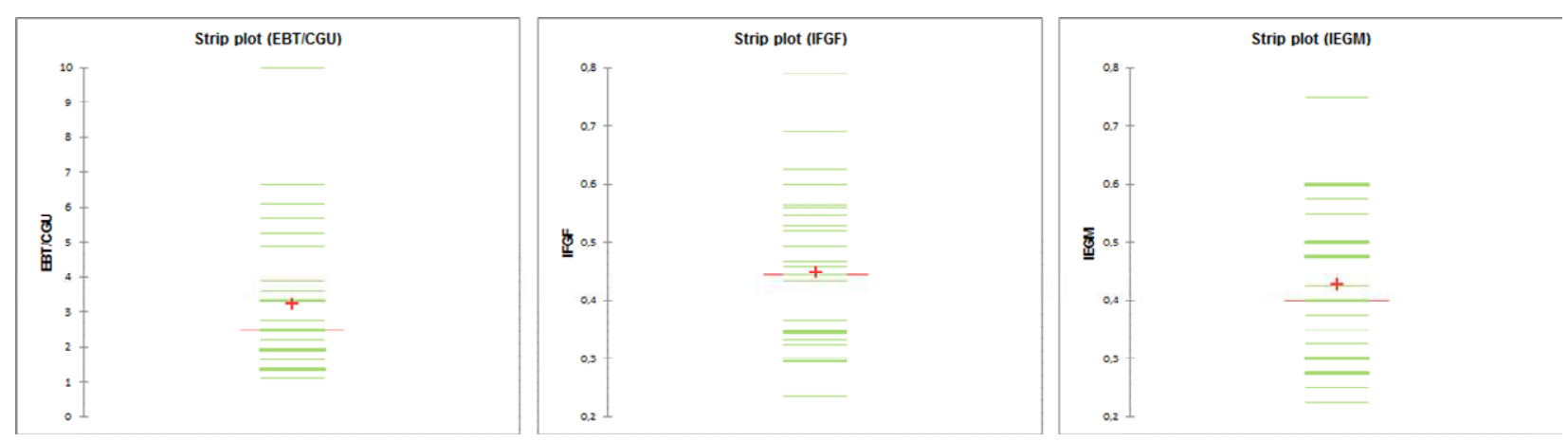

Figura №2. Gráficos Strip Plot de los indicadores EBC, IFGF e IEGM

Fuente: Elaboración Propia

Los gráficos que fueron ploteados y que presentan la normalidad de cada indicador son presentados a continuación, porque todos los indicadores se encuentran con la distribución próxima y regular a la recta del gráfico.
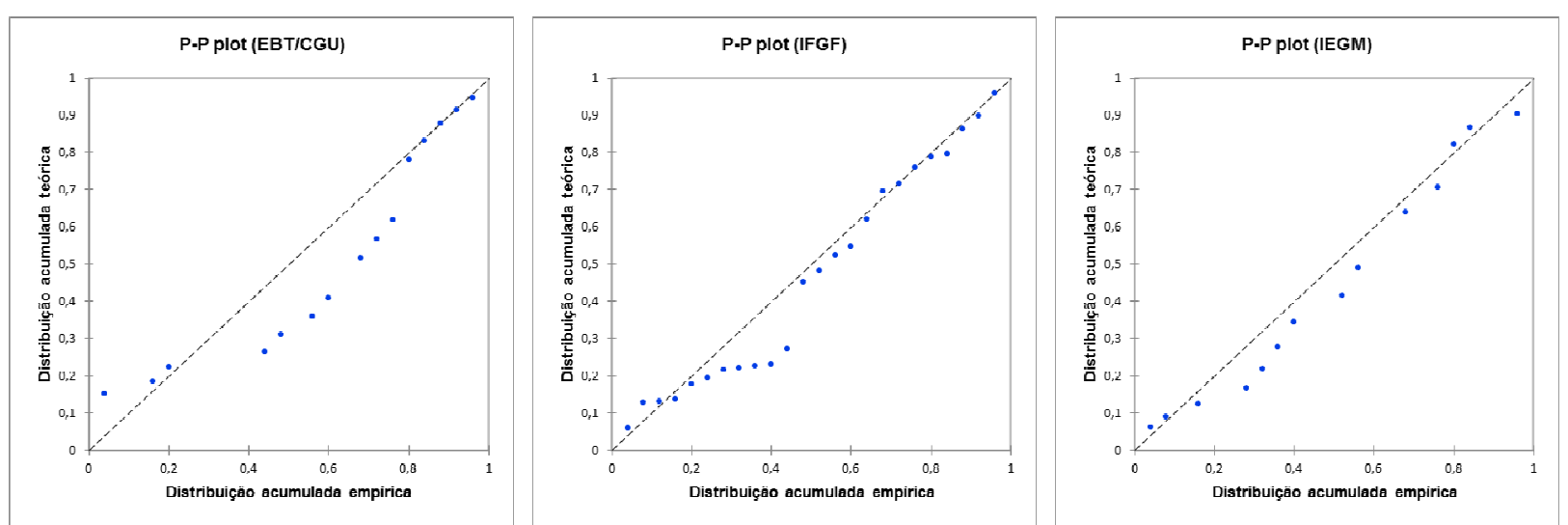

Figura №3. Gráficos de distribución acumulada empírica de los indicadores EBC, IFGF e IEGM

Fuente: Elaboración Propia

Luego del análisis presentado, fueron realizadas nuevas tabulaciones, arreglos y correlaciones entre el indicador EBT/CGU y los indicadores IFGF e IEGM y fueron confirmadas las siguientes hipótesis:

$\mathrm{H}_{5}=$ Existe una correlación positiva y moderada de 0,359 entre el indicador EBT y el IFGF en municipios de Alagoas;

"Visión de Futuro" Año 16, Volumen Nº 23 N¹, Enero - Junio 2019 - Pág. 75 - 96

URL de la Revista: http://revistacientifica.fce.unam.edu.ar/

URL del Documento: http://revistacientifica.fce.unam.edu.ar/index.php?option=com_content\&view=article\&id=492\&ltemid=101

ISSN 1668 - 8708 - Versión en Línea

E-mail: revistacientifica@fce.unam.edu.ar 
$\mathrm{H}_{6}=$ Existe una correlación positiva y moderada de 0,497 entre el indicador EBT y el IEGM en municipios de Alagoas.

Una vez identificadas las independencias entre las columnas, se procedió a la construcción de la tabla con la utilización del Análisis de Correspondencia Múltiple:

Tabla №6. Correlación entre los indicadores

\begin{tabular}{lrrrrr}
\hline & Peso (relativo) & Distância & Distância $^{2}$ & Inércia & Inércia relativa \\
\hline EBT/CGU & 0,787 & 0,085 & 0,007 & 0,006 & 0,495 \\
IFGF & 0,109 & 0,049 & 0,002 & 0,000 & 0,023 \\
IEGM & 0,104 & 0,043 & 0,002 & 0,000 & 0,017 \\
\hline
\end{tabular}

Perfis (colunas):

\begin{tabular}{|c|c|c|c|c|}
\hline & EBT/CGU & IFGF & IEGM & Média \\
\hline Maceió & 0,123 & 0,047 & 0,047 & 0,072 \\
\hline Murici & 0,082 & 0,061 & 0,070 & 0,071 \\
\hline Messias & 0,075 & 0,050 & 0,051 & 0,059 \\
\hline São Sebastião & 0,070 & 0,039 & 0,047 & 0,052 \\
\hline São José da Tapera & 0,065 & 0,050 & 0,056 & 0,057 \\
\hline Arapiraca & 0,060 & 0,046 & 0,054 & 0,053 \\
\hline Tanque d'Arca & 0,048 & 0,026 & 0,026 & 0,033 \\
\hline São José da Laje & 0,044 & 0,041 & 0,037 & 0,041 \\
\hline Major Isidoro & 0,041 & 0,026 & 0,037 & 0,035 \\
\hline Palmeira dos Índios & 0,041 & 0,033 & 0,035 & 0,036 \\
\hline Marechal Deodoro & 0,034 & 0,053 & 0,026 & 0,038 \\
\hline Branquinha & 0,031 & 0,049 & 0,028 & 0,036 \\
\hline Porto Real do Colégio & 0,031 & 0,031 & 0,028 & 0,030 \\
\hline Taquarana & 0,027 & 0,044 & 0,056 & 0,042 \\
\hline Barra de São Miguel & 0,024 & 0,039 & 0,037 & 0,034 \\
\hline Feliz Deserto & 0,024 & 0,027 & 0,044 & 0,032 \\
\hline Limoeiro de Anadia & 0,024 & 0,031 & 0,030 & 0,028 \\
\hline Olivença & 0,024 & 0,030 & 0,040 & 0,031 \\
\hline Santana do Mundaú & 0,024 & 0,056 & 0,023 & 0,034 \\
\hline Traipu & 0,024 & 0,070 & 0,056 & 0,050 \\
\hline União dos Palmares & 0,020 & 0,031 & 0,044 & 0,032 \\
\hline Jundiá & 0,017 & 0,041 & 0,044 & 0,034 \\
\hline Matriz de Camaragibe & 0,017 & 0,030 & 0,033 & 0,027 \\
\hline Satuba & 0,017 & 0,021 & 0,021 & 0,020 \\
\hline Cacimbinhas & 0,014 & 0,029 & 0,028 & 0,023 \\
\hline Soma & 1 & 1 & 1 & 1 \\
\hline
\end{tabular}

Fuente: Elaboración Propia

Luego de identificadas las correlaciones, se procedió con el análisis de correspondencia para probar la independencia entre los indicadores y los datos identificados en los municipios, siendo encontrados los siguientes resultados:

\footnotetext{
"Visión de Futuro" Año 16, Volumen N²3 N¹, Enero - Junio 2019 - Pág. 75 - 96

URL de la Revista: http://revistacientifica.fce.unam.edu.ar/

URL del Documento: http://revistacientifica.fce.unam.edu.ar/index.php?option=com_content\&view=article\&id=492\&ltemid=101

ISSN 1668 - 8708 - Versión en Línea

E-mail: revistacientifica@fce.unam.edu.ar
} 
Tabla №7. Test de independencia entre las filas y las columnas

\begin{tabular}{|c|c|}
\hline C (Valor observado) & 6,605 \\
\hline C (Valor crítico) & 65,171 \\
\hline GL & 48 \\
\hline p-valor & 1,000 \\
\hline alfa & 0,05 \\
\hline \multicolumn{2}{c}{ Fuente: Elaboración Propia }
\end{tabular}

Interpretación del test:

H0: Las filas y las columnas de la tabla son independientes.

Ha: Existe una dependencia entre las filas y las columnas de la tabla.

Como el $p$-valor calculado es mayor que el nivel de significancia alfa $=0,05$, no se rechaza la hipótesis nula $\mathrm{H} 0$. El riesgo de rechazar la hipótesis nula $\mathrm{H} 0$ cuando esta es verdadera es del 100\%. Tau de Goodman y Kruska es de 0,032.

A continuación, se verificó la tabla de Burt, que es una matriz simétrica utilizada para ayudar a visualizar y analizar relaciones entre las variables con el resultado de la confrontación entre los indicadores EBT, IFGF y IEGM, presentando una inercia total de 19,25, muy significativa y siendo adecuada para el análisis de los datos:

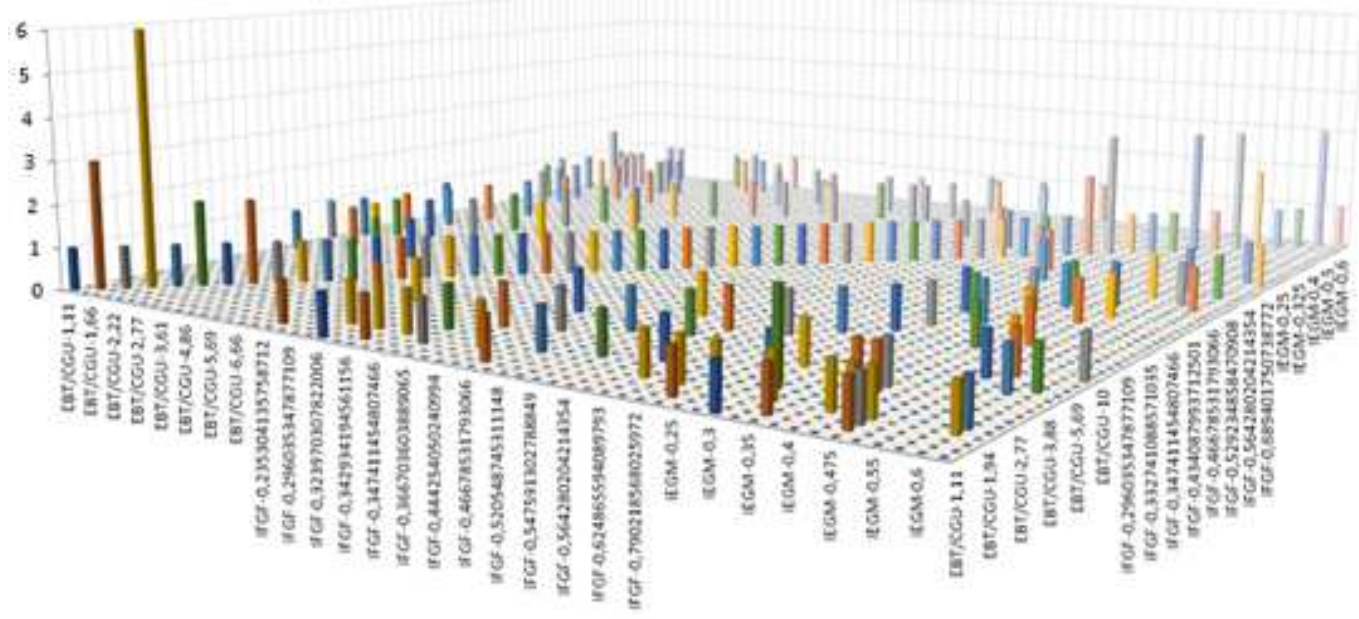

Figura 4. Visualización 3D de la tabla de Burt Fuente: Elaboración Propia

Finalmente, se presenta un gráfico con relación a la asimetría de las variables, sugiriendo una posible asociación entre los indicadores EBT/CGU, IFGF/FIPLAN e IEGM/IRB:

\footnotetext{
"Visión de Futuro" Año 16, Volumen N²3 N¹, Enero - Junio 2019 - Pág. 75 - 96

URL de la Revista: http://revistacientifica.fce.unam.edu.ar/

URL del Documento: http://revistacientifica.fce.unam.edu.ar/index.php?option=com_content\&view=article\&id=492\&ltemid=101

ISSN 1668 - 8708 - Versión en Línea

E-mail: revistacientifica@fce.unam.edu.ar
} 


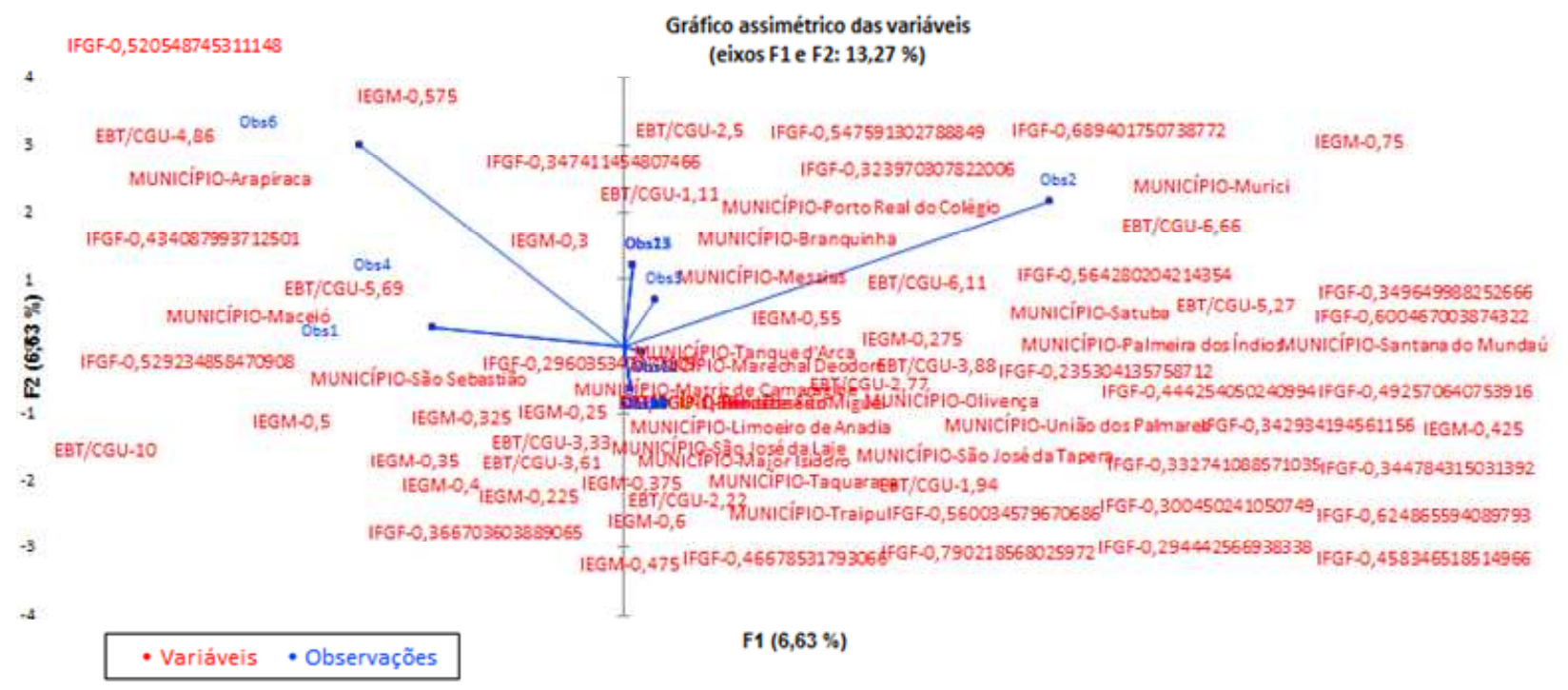

Figura 5. Gráfico asimétrico de las variables

Fuente: Elaboración Propia

La interpretación es que hay una asimetría entre los indicadores y municipios, pues cuando los datos parten cerca del origen, se puede reflexionar que la variable posee una asociación significativa con su categoría más frecuente y que puntos distantes del origen indican lo contrario, o sea, que la variable posee una asociación significativa con una categoría que no es la más frecuente.

\section{CONCLUSIÓN}

Este trabajo buscó comparar indicadores de transparencia y resultados mediante los resultados en órganos oficiales, buscando relaciones entre los mismos, desde la perspectiva de dar continuidad a las discusiones sobre gobernanza electrónica a través de sus portales públicos, así como poner a disposición los resultados para la sociedad alagoana. Además, como objetivos específicos se buscó una correlación de los resultados de los índices de la EBT/CGU, IEGM/IRB, IFGF/FIRJAN con otros índices de naturaleza socioeconómica de los municipios investigados.

Fueron analizados indicadores de transparencia, gestión y resultados a través del análisis de los índices de 25 municipios de Alagoas, comparados entre sí y, a continuación, presentando que existe correlación positiva entre los mismos, así como la existencia de asociación entre los indicadores, lo que es importante para continuar los estudios en esta línea. No obstante, cuando fueron analizados los 102 municipios, solamente el 25\% presentó condiciones de investigación, lo que significa que aún no se encuentran presentes los requisitos de gobernanza electrónica y transparencia requeridos por la

"Visión de Futuro" Año 16, Volumen N² 23 N¹, Enero - Junio 2019 - Pág. 75 - 96

URL de la Revista: http://revistacientifica.fce.unam.edu.ar/

URL del Documento: http://revistacientifica.fce.unam.edu.ar/index.php?option=com_content\&view=article\&id=492\&ltemid=101

ISSN 1668 - 8708 - Versión en Línea

E-mail: revistacientifica@fce.unam.edu.ar 
legislación y por la propia sociedad para la práctica de ciudadanía y participación política, sin embargo, los indicadores de transparencia oficiales tienen similitudes y normalidad en los resultados presentados, pero todavía está distante de su función propia y esencial de presentar la realidad de la administración para la sociedad y para las prácticas de democracia y participación popular.

El estudio presenta limitaciones justamente debido a la ausencia de información en los municipios alagoanos, sugiriendo que para estudios futuros sea ampliada esta investigación para otros estudios o grupos de municipios con características semejantes.

Finalmente, se verifica que es importante continuar acompañando y correlacionando los diversos indicadores de control, gestión y resultados, pues muchos municipios no adoptan prácticas de gobernanza digital de manera general, a pesar de la posibilidad de implementarlas de manera simple, tales como disponibilidad de legislación, documentos públicos, información sobre licitaciones y concursos, estados financieros, contactos de los gestores y noticias sobre hechos importantes del municipio.

\section{REFERENCIAS}

An, Y., Davey. H., \& Eggleton., I. R. C. (2011). Towards a comprehensive theoretical framework for voluntary IC disclosure. Journal of Intellectual Capital, V. 4 (12), p. 1-20.

Bernardes, M. et al., (2015). Ranking de los ayuntamientos de la región sur de Brasil: una evaluación basada en los criterios establecidos en la ley de acceso a la información. Revista de Administração Pública, 49 (3), p. 761-792. Recuperado de: https://dx.doi.org/10.1590/0034$\underline{7612119279}$

Beuren, I. M., et al., (2013). Práticas de governança eletrônica e eficiência na utilização das receitas: uma análise nos estados brasileiros. RAP: Revista Brasileira de Administração Pública, V. 47 (2).

Cordeiro, A., Martins, et al., (2012). Transparência da gestão pública municipal: um estudo a partir dos portais eletrônicos dos maiores municípios brasileiros. Rev. Adm. Pública, Rio de Janeiro, V. 46 (1). Recuperado de <http://www.scielo.br/scielo.php?script=sci_arttext\&pid=S0034-76122012 000100008\&lng=en\&nrm=iso> http://dx.doi.org/10.1590/S0034-76122012000100008.

De Souza, Fabia Jaiany Viana (2013). Índice de transparência municipal: um estudo nos municípios mais populosos do Rio Grande do Norte. Revista de Gestão, Finanças e Contabilidade, V 3 (3), p. 94-113.

De Meiroz Dias, I. (2011). A relação entre reforma da administração pública e tecnologias de informação no governo do estado de São Paulo (Tese de Doutorado). Universidade de São Paulo, São Paulo, Brasil.

\footnotetext{
"Visión de Futuro" Año 16, Volumen N²3 N¹, Enero - Junio 2019 - Pág. 75 - 96

URL de la Revista: http://revistacientifica.fce.unam.edu.ar/

URL del Documento: http://revistacientifica.fce.unam.edu.ar/index.php?option=com_content\&view=article\&id=492\&ltemid=101

ISSN 1668 - 8708 - Versión en Línea

E-mail: revistacientifica@fce.unam.edu.ar
} 
Índices de Transparencia y Gestión en las Entidades Públicas como Herramienta de Control y Desempeño: una comparación entre Indicadores Municipales en Alagoas - Brasil

Pacheco de Freitas, I. L. (2015) E-governo e accountability nas democracias: aspectos teóricos e desenvolvimentos recentes no Brasil (Tese de Doutorado em Ciência Política). Universidade Federal do Rio Grande do Sul, Porto Alegre, Brasil.

Freitas, R. K. V., \& Luft, M. C. M. S., (2014). Índice de governança eletrônica nos municípios: uma análise do estado de Sergipe. RECADM: Revista Eletrônica de Ciência Administrativa, V. 13, p. 56-73.

Gil, A. C. (2017). Métodos e Técnicas de Pesquisa Social. São Paulo, Brasil, Editora Atlas.

Instituto Brasileiro De Geografia E Estatística - IBGE. (2012). Estimativas de população. Recuperado de: <http://www.ibge.gov.br/home/estatistica/populacao/estimativa 2012 / estimativa_tcu.shtm >.

Lemos, A.,y Lévy, P. (2010). O Futuro da internet: em direção a uma ciberdemocracia planetária. São Paulo, Brasil, Paulos.

Levi-Faur, . (2012.). Oxford Handbook of Governance. New York, EEUU, Oxford University Press.

Machado-Da-Silva, C. L., et al., (2006). Campos organizacionais: seis diferentes leituras e a perspectiva de estruturação. Rev. adm. contemp. V. 10, p. 159-196. Recuperado de: <http://www.scielo. br/scielo. php?script=sci_arttext\&pid=S141565552006000500009\&Ing=en\&nrm=iso >. http:// dx.doi.org/10.1590/ S1415-65 552006000500009.

Magalhães, F. R., et al., (2012). Rumo a um quadro teórico abrangente para as práticas de Internet Financial Reporting no setor público. XXXVI EnANPAD, Encontro da ANPAD, Rio de Janeiro, Brasil.

Matos, N. B., et al., (2013). Avaliação de portais de transparência dos 30 municípios mais populosos da Região Nordeste. Registro Contábil - RECONT, V. 4, p. 17-35.

Mello, Gilmar Ribeiro de y Slomski, Valmor. (2010). Índice de governança eletrônica dos estados Brasileiros: no âmbito do poder executivo. JISTEM J.Inf.Syst. Technol. Manag. V. 7 (2). Recuperado de: <http://www.scielo.br/scielo.php?script=sci_arttext\&pid=S180717752010000200007\&lng=pt\&nrm=iso >. http://dx.doi. org/10.4301/S1807-17752010000200007

De Moura, G. D., et al., (2015). Análise das práticas de governança eletrônica de municípios do Estado de Santa Catarina. Ágora: revista de divulgação científica, V. 20(2), 84-106.

De Moura, G. D. et al., (2013). Práticas de governança eletrônica em municípios da região sul do Brasil: uma análise sob a ótica da teoria da legitimidade. Gestão Pública: Práticas e Desafios. V. 4, (7), 2013.

Peters, B. Guy. Governance and Sustainable Development Policies, 2012.

"Visión de Futuro" Año 16, Volumen N² 23 N¹, Enero - Junio 2019 - Pág. 75 - 96

URL de la Revista: http://revistacientifica.fce.unam.edu.ar/

URL del Documento: http://revistacientifica.fce.unam.edu.ar/index.php?option=com_content\&view=article\&id=492\&ltemid=101

ISSN 1668 - 8708 - Versión en Línea

E-mail: revistacientifica@fce.unam.edu.ar 
Raupp, F. M. y Pinho, A. G. de. (2010). Prestação de Contas por meio de Portais Eletrônicos de Câmaras Municipais: um estudo de caso em Santa Catarina antes e após a Lei da Transparência. Encontro de Administração Pública e Governança, Vitória/ES.

Raupp, F. M. y Pinho, J. A. G. (2012). Possibilidades de Participação no Legislativo Municipal por meio de Portais Eletrônicos. Cadernos Gestão Pública e Cidadania, V. 17 (61).

Raupp, F.M. y Pinho, J.A.G. (2013). Accountability em câmaras municipais: uma investigação em portais eletrônicos. R.Adm., V.48 (4), p.770-782.

Sales, T. S. (2013). Transparência, controle social, eficiência e democracia na era da nova gestão pública. Systemas-Revista de Ciências Jurídicas e Econômicas, V. 5, p. 54-69.

Souza, F. J. V., et al., (2013). Índice de Transparência Municipal: um estudo nos municípios mais populosos do Rio Grande do Norte. 13ํㅡㄹ Congresso USP de controladoria e contabilidade FEA/USP.

Souza, F. J. (2014). Práticas de governança eletrônica: um estudo nos portais dos municípios mais populosos do Brasil. Dissertação de Mestrado. Programa Multinstitucional e Inter-regional de Pós-graduação em Ciências Contábeis. UNB.

\section{RESUMEN BIOGRÁFICO}

\section{Artur Angelo Ramos Lamenha}

Graduado Ciencias Contables - AL (1995). Esp. Psicología Organizacional (2015); Esp. Economía (2012); Esp. Contabilidad y Auditoría (1998). Magister Gestión Pública (2010). Doctorando en administración - UNAM. Profesor UFAL (FEAC) y del Centro de Estudios Superiores de Maceió - CESMAC en cursos de especialización de las áreas de Administración, Administración Pública y Ciencias Contables. Analista en Gestión - Fundación Instituto Brasileño de Geografía y Estadística - IBGE. Experiencia en Auditoria, Contabilidad empresarial, pública y de Instituciones Sociales, y actividades de Planeamiento, Presupuesto y Gestión Financiera en el Gobierno Federal.

\section{Juedir Viana Teixeira}

Graduado Ciencias administrativas - Facultades Integradas Simonsen (1979). Ciencias Contables - Facultades Integradas Simonsen (1981). MBA Gestión Minorista - FGV (2003). Maestría Gestión Estratégica de Negocios - UNaM Argentina (2017), doctorando en administración UNAM. Trabajó 25 años en Petrobras Distribuidora como administrador, ocupando las funciones de Gerente de Operaciones, Gerente Financiero, Gerente de ventas y Asistente de director. Actúa desde hace 35 años como profesor universitario y en los últimos 20 años como profesor y coordinador de cursos de Posgrado - MBA y grado. Larga experiencia como consultor en el área de gestión, siendo coautor de 3 libros sobre el tema.

\footnotetext{
"Visión de Futuro" Año 16, Volumen N²3 N¹, Enero - Junio 2019 - Pág. 75 - 96

URL de la Revista: http://revistacientifica.fce.unam.edu.ar/

URL del Documento: http://revistacientifica.fce.unam.edu.ar/index.php?option=com content\&view=article\&id=492\&ltemid=101

ISSN 1668 - 8708 - Versión en Línea

E-mail: revistacientifica@fce.unam.edu.ar
} 